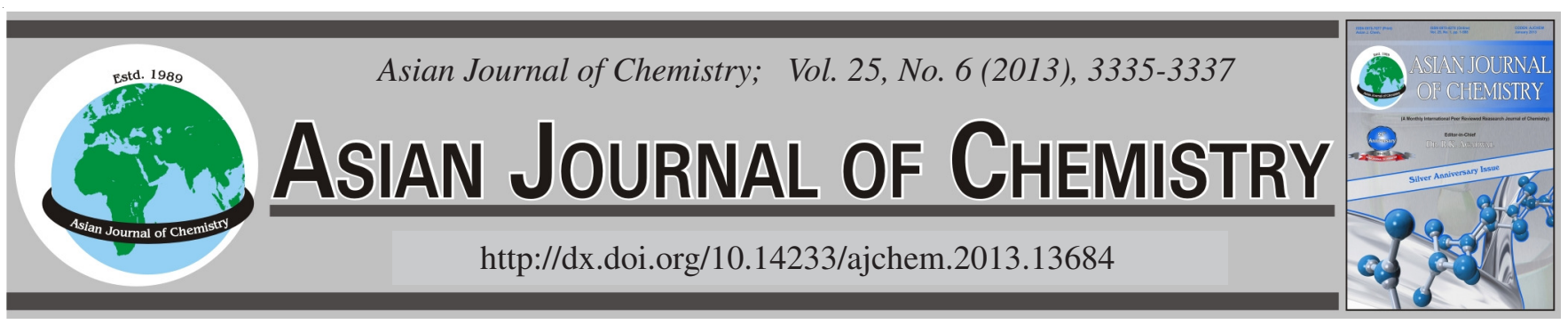

\title{
Simultaneous Determination of Five Compounds by HPLC and Its Application to the Suitable Harvest Time for Medicinal Plant Curcuma wenyujin
}

\author{
Yuan Zhang, Xiao-Jun Cai, Yu-Ping Xu, Yu Pan and Xiang Zheng*
}

School of Pharmaceutical Sciences, Wenzhou Medical College, Wenzhou 325035, Zhejiang Province, P.R. China

*Corresponding author: Tel/Fax: +86 577 86699156; E-mail: xiangzheng1978@yahoo.cn

(Received: 6 March 2012;

Accepted: 19 December 2012)

AJC-12580

\begin{abstract}
The methods for simultaneous determination of five compounds including $\beta$-elemene, curcumine, curcumol, curdione and germacrone, were developed using a reversed-phase $\mathrm{C}_{18}$ column. All calibration curves were linear $(r>0.9993)$ over the range of tested concentration. This method showed good repeatability for the quantification of these five compounds with intra-day and inter-day variations of less than 1.42 and $1.76 \%$, respectively. Furthermore, the validated method was applied to determine four active components in rhizome extract from different developmental stages of Curcuma wenyujin. The results showed the suitable harvest time can be suggested before and after January, which is helpful to control their quality.
\end{abstract}

Key Words: Curcuma, HPLC, Determination.

\section{INTRODUCTION}

Curcuma belongs to the family Zingiberaceae. According to the record of China Pharmacopoeia, the rhizomes of three species Curcuma distributed in China, including $C$. phaeocaulis, $C$. kwangsiensis and $C$. wenyujin have been used as traditional Chinese medicine for thousands of years. The modern pharmacological study indicated the rhizome of three Curcuma species possess antitumor ${ }^{1-4}$ and antiviral activities ${ }^{5-7}$, reduce blood lipid ${ }^{8-11}$ and enhances immune function ${ }^{11-15}$. It is reported that the compounds such as $\beta$-elemene, curcumine, curcumol, curdione and germacrone are thought to be the main biologically active ingredients in their extracts $2,6,7,10,11,15-19$. Therefore, quantitative determination of these compounds is significant for pharmacological study and quality control of plant Curcuma.

Chinese traditional medicine and herbs (TCMs) are complex system, whose quality control depends on various factors such as geographic location, season and time of collection, natural growth environment, pose-harvest processing and storage $^{20}$. This results in difficulty in their quality control. To obtain reliable and stable medical materials, the project of "Good Agriculture Practice (GAP)" was proposed by Chinese State Food and Drug Administration (SFDA). By virtue of modern advanced and sophisticated technique, Good Agriculture Practice aimed at normalization of study, development, plant and administration for traditional Chinese medicines. Usually, within a Good Agriculture Practice base, the differences of geographic location have a marginal impact on quality control of traditional Chinese medicines, but season and time of collection might have a greater impact on their quality of medical material.

Gas chromatography-flame ionization detection ${ }^{21-23}$, gas chromatography-mass spectrometry (GC-MS) ${ }^{24-26}$ and highperformance liquid chromatography (HPLC) ${ }^{27-29}$ methods have been reported to determine some active components from Curcuma plant in the past 10 years. For GC-MS, some heatsensitive components such as germacrone and furanodiene ${ }^{26-31}$ and the components with higher-molecular-weight such as curcumine, if they were not derivatized, can degrade or not detected and even would result in wrong analytical results. As such, HPLC method was the preferable choice to determine these secondary metabolites from Curcuma plant. One or more components in rhizome extracts were developed by HPLC ${ }^{27-29}$. However, there are no methods of simultaneous determination of these five active components. In addition, there are few reports on their accumulation in the developmental stages of plant Curcuma so far.

The present work aimed at simultaneous determination of five active components. Further, on account of their accumulation and dried weight of $C$. wenyujin rhizome at different harvest times, the suitable harvest time was suggested.

\section{EXPERIMENTAL}

The plant $C$. wenyujin was rooted and cultivated at Good Agricultural Practice (GAP) base located in Ruian, Zhejiang Province of China. They were collected about every half month 
from September 16th to the next March 2nd. The summary of collection was twelve batches and four $C$. wenyujin plants were collected at each harvest time point. One sample consisted of one plant, giving four samples at each same harvest time. The information of total 48 samples was listed in Table-1.

Sample preparation: The rhizome was boiled for $40 \mathrm{~min}$ as soon as they were collected, then parched at $35^{\circ} \mathrm{C}$ until constant weight. The samples to be tested were cut into smaller pieces and ground into a powder, then passed through a 20mesh $(0.9 \mathrm{~mm})$ sieve. Each sample $(1 \mathrm{~g})$ was weighed accurately and then extracted by ultrasonic techniques with $50 \mathrm{~mL}$ of methanol for $1 \mathrm{~h}$. After that, a portion of methanol was added in order to keep a fixed weight before and after ultrasonic extraction. Finally, the $1 \mathrm{~mL}$ of supernatant was filtered through $0.45 \mu \mathrm{m}$ of filter membrane. A $20 \mu \mathrm{L}$ aliquot of the filtered solution was injected for HPLC analysis.

Methanol and mobile phase of acetonitrile for HPLC grade were purchased from Merck (Darmstadt, Germany). Water for experiment was prepared using a Millipore Milli-Q Plus system (Millipore, Bedford, MA, USA). The reference compounds of curcumol, germacrone, $\beta$-elemene and curcumine, with over $99 \%$ of purity, were purchased from Chinese National Institute for Control of Pharmaceutical and Biological Products, Beijing, in China. Curdione was kindly provided by Professor Ke-xin Huang worked in the school of Pharmaceutical Sciences, Wenzhou Medical College.

HPLC was performed with an Agilent Series 1100 (Agilent Technologies, USA) liquid chromatography instrument coupled to diode array detection (DAD) system, a quaternary pump, vacuum degasser and an autosampler. A Hypersil ODS column $(250 \mathrm{~mm} \times 4.0 \mathrm{~mm}$ I.D., $5 \mu \mathrm{m})$ was used for the separation. The mobile phase consisted of A (water) and B (acetonitrile). Based on good separation for all components in extracts, the instrument parameters of elution conditions were as following: $30-47 \% \mathrm{~B}$ in $0-15 \mathrm{~min} ; 47 \% \mathrm{~B}$ in $15-25 \mathrm{~min} ; 47-60 \% \mathrm{~B}$ in 25-35 min; $60-90 \% \mathrm{~B}$ in $35-50 \mathrm{~min}$; $90-100 \% \mathrm{~B}$ in $50-60$ min and then balanced for $5 \mathrm{~min}$. The flow-rate was $1 \mathrm{~mL}$ $\mathrm{min}^{-1}$, the column temperature was kept at $30^{\circ} \mathrm{C}$. The samples were detected with DAD at $214 \mathrm{~nm}$.

\section{RESULTS AND DISCUSSION}

Calibration curves: The stock solutions of methanol with five reference compounds were prepared and diluted to eight series of standard concentration for the construction of calibration curves. Each normal concentration was analyzed in triplicate and then the calibration curves were established by plotting the peak areas versus corresponding concentration of each analyte. The results were given in Table-2.

Limit of detection and limit of quantification: The stock solution of methanol with five reference compounds was diluted to a series of proper concentrations for HPLC-DAD analysis. Under the present chromatographic conditions, the limit of detection (LOD) and limit of quantification (LOQ), defined as a signal-to-noise ratio $(\mathrm{S} / \mathrm{N})$ of $c a .3$ and 10 , respectively, were also shown in Table-2.

Precision and accuracy: Precision and accuracy of the assay were investigated. For intra-day and inter-day variability, the mixed standards solution (including $\beta$-elemene, $8.85 \mu \mathrm{g}$ / $\mathrm{mL}$; curcumine, $208.0 \mu \mathrm{g} / \mathrm{mL}$; curcumol, $68.0 \mu \mathrm{g} / \mathrm{mL}$; curdione $106.0 \mu \mathrm{g} / \mathrm{mL}$; germacrone, $106.0 \mu \mathrm{g} / \mathrm{mL}$ ) was examined for six replicates within one day and consecutive 3 days by the same way, respectively. Relative standard deviation (RSD) in variant of intra-day and inter-day for five analytes were 0.47 1.42 and $0.66-1.76 \%$, respectively. The recovery was tested by adding known amount standard solution (the concentration as above) into a certain amount $(0.5 \mathrm{~g})$ of medical material. The mixture was extracted and detected by the mentioned method above. Five replicates were performed for the test. Recovery and relative standard deviation (RSD) for five analytes were $97.3-102.6$ and $0.52-2.84 \%(n=5)$, respectively.

Quantification of four compounds: The content of four bioactive compounds (Fig. 1) in samples was determined by applying the calibration curve of each investigated compound. Table-3 showed the summary results. The results indicated that the accumulation content of four characteristic compounds was irregularly fluctuated with different harvest times. The content of curcumine, curdione, $\beta$-elemene and germacrone is higher at earlier harvest time such as September 16th and October 2nd, while from Table-1, the dried weight of samples is relatively light $(<134.0 \mathrm{~g})$. From October 17 th to the next January 2nd, their content basically remained a stable constant, but before November 17 th, the dried weight of samples is still relatively lighter. Until after December 2nd, the dried weight of samples exceeds $300 \mathrm{~g}$. Generally, compared with above collection time, the next January 17th to March 2nd, their

TABLE-1

COLLECTION TIME AND SAMPLES NUMBER OF SAMPLES FROM C. wenyujin PLANT

\begin{tabular}{|c|c|c|c|c|c|c|c|}
\hline Date $^{\mathrm{a}}$ & $\mathrm{SN}^{\mathrm{b}}$ & Date & SN & Date & SN & Date & SN \\
\hline $16^{\text {th }}$ Sept & $1-4$ & $2^{\text {nd }}$ Nov & 13-16 & $17^{\text {th }}$ Dec & $25-28$ & $2^{\text {nd }} \mathrm{Feb}$ & $37-40$ \\
\hline $2^{\text {nd }}$ Oct & $5-8$ & $17^{\text {th }}$ Nov & $17-20$ & $2^{\text {nd }} \operatorname{Jan}$ & $29-32$ & $17^{\text {th }} \mathrm{Feb}$ & $41-44$ \\
\hline $17^{\text {th }}$ Oct & $9-12$ & $2^{\text {nd }} \mathrm{Dec}$ & $21-24$ & $17^{\text {th }} \mathrm{Jan}$ & $33-36$ & $2^{\text {nd }}$ Mar & $45-48$ \\
\hline
\end{tabular}

${ }^{\mathrm{a}}$ Date is the collection time. ${ }^{\mathrm{b}}$ Samples number.

TABLE-2

LINEAR REGRESSION DATA, LOD AND LOQ OF FIVE INVESTIGATED COMPONENTS FROM RHIZOME

\begin{tabular}{|c|c|c|c|c|c|}
\hline \multirow{2}{*}{ Analytes } & \multicolumn{3}{|c|}{ Linear regression data } & \multirow{2}{*}{ LOD $(\mu \mathrm{g})$} & \multirow{2}{*}{ LOQ $(\mu \mathrm{g})$} \\
\hline & Regressive equation & Test range $(\mu \mathrm{g} / \mathrm{mL})$ & Correlation & & \\
\hline Curcumine & $y=6.44 x-95.70$ & $52.0-520.0$ & 0.9995 & 0.45 & 1.30 \\
\hline Curcunol & $y=5.84 x-19.41$ & $6.8-340.0$ & 0.9995 & 0.53 & 5.10 \\
\hline Curdione & $y=3.54 x-10.15$ & $10.6-530.0$ & 0.9997 & 0.53 & 1.80 \\
\hline Germacrone & $y=23.17 x-3.16$ & $10.6-530.0$ & 0.9999 & 0.52 & 1.32 \\
\hline$\beta$-Elemene & $y=618.18 x-123.25$ & $1.77-17.7$ & 0.9993 & 0.35 & 2.20 \\
\hline
\end{tabular}




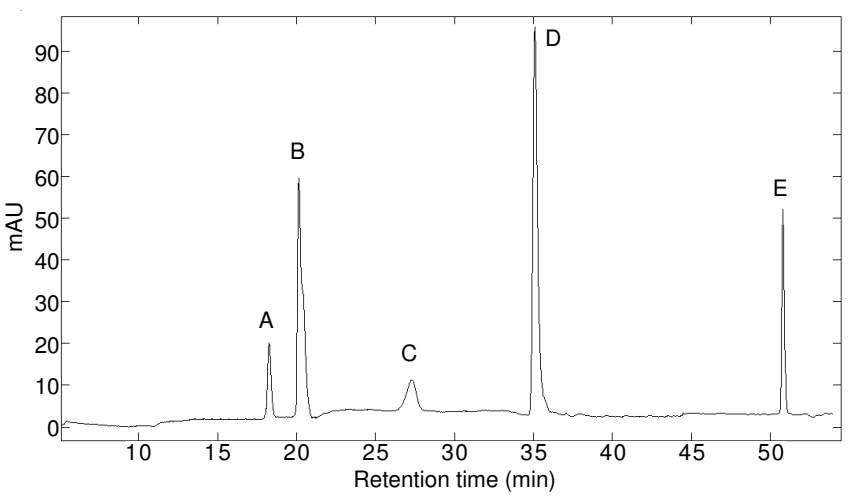

Fig. 1. HPLC chromatograms of mixed standards. The analytes were monitored with diode array detector at $214 \mathrm{~nm}$. (A) curdione; (B) curcumine; (C) curcumol; (D) germacrone; (E) $\beta$-elemene

TABLE-3

CONTENTS $(\mathrm{mg} / \mathrm{g})$ OF FOUR COMPOUNDS AND MEAN DRY WEIGHT (g) OF RHIZOME IN $C$. wenyujin PLANT AT THE DIFFERENT HARVEST TIMES

\begin{tabular}{cccccc}
\hline Date & Weight $^{\mathrm{a}}$ & Curcumine $^{\mathrm{b}}$ & Curdione $^{\mathrm{b}}$ & Germacrone $^{\mathrm{b}}$ & Elemene $^{\mathrm{b}}$ \\
\hline 0916 & 100.10 & 14.530 & 6.729 & 7.243 & 0.301 \\
1002 & 133.28 & 12.057 & 6.117 & 5.954 & 0.221 \\
1017 & 179.23 & 11.849 & 5.402 & 5.676 & 0.205 \\
1102 & 233.52 & 10.894 & 4.991 & 4.766 & 0.205 \\
1117 & 274.12 & 11.597 & 4.871 & 5.409 & 0.209 \\
1202 & 304.28 & 12.037 & 4.879 & 5.477 & 0.241 \\
1217 & 318.54 & 11.884 & 5.155 & 5.663 & 0.197 \\
0102 & 328.00 & 11.976 & 5.201 & 5.531 & 0.198 \\
0117 & 333.78 & 11.734 & 5.105 & 5.571 & 0.185 \\
0202 & 337.49 & 11.855 & 5.051 & 5.100 & 0.180 \\
0217 & 330.68 & 12.148 & 5.142 & 5.378 & 0.207 \\
0302 & 325.26 & 12.324 & 5.595 & 5.208 & 0.185 \\
\hline
\end{tabular}

${ }^{a}$ The mean dry weight of four $C$. wenyujin plants at the same harvest time. ${ }^{\text {b}}$ The data was present as average content of four samples.

accumulation content decreased, but the dried weight varied slightly. Thus, based on both the accumulation content of different components and dried weight of samples, the suitable time was suggested from early December to the next early January. It should be noted that, though curcumol was regarded as a main bioactive component for plant Curcuma, it was not detected during the developmental periods of plant $C$. wenyujin, which was consistent with some previous reports ${ }^{25,26,29}$. This phenomenon might reflect the geographic location have an important impact on the metabolism related with curcumol.

\section{Conclusion}

This work developed a HPLC method for simultaneous determination of 5 characteristic compounds including curcumine which are not available for detected using GC because of its higher boiling point. Then the developed method was applied to determination of extracts from the developmental stages of $C$. wenyujin rhizome. The results showed that the suitable harvest time for $C$. wenyujin was suggested from early December to the next early January, which is helpful to control the quality and drug safety in clinics. In addition, the results of chemical fingerprints of extracts indicated that there are no distinct phytochemical differences in different growth stages of $C$. wenyujin, but their content are constantly fluctuating with season and time of collection, which provide a useful knowledge about $C$. wenyujin.

\section{ACKNOWLEDGEMENTS}

This work was supported by the Nature Foundation Committee of Wenzhou in China (Grants Nos. Y20070057) and Traditional Chinese Medicine Research Project of Zhejiang Province (Grants Nos. 2010ZB087). The authors are grateful to the staff of the Good Agricultural Practice (GAP) base of plant $C$. wenyujin for the collection of samples.

\section{REFERENCES}

1. J.P. Jiang, Trad. Chin. Med, 2, 62 (2000).

2. X.H. Nie, Z.H. Ao, G.Y. Yin and W.Y. Tao, Chin. Pharm. Biotechnol., 3, 152 (2003).

3. F.R. Carvalho, R.C. Vassao, M.A. Nicoletti and D.A. Nicoletti, J. Venom Anim Toxins, 16, 324 (2010).

4. B.P. Priosoeryanto, E.J. Stephani, R. Sari, L.K. Darusman, E.D. Purwakusumah, W. Nurcholis and R. Tiuria, Thai. J. Vet. Med., 39, 447 (2009).

5. H.J. Kim, H.S. Yoo, J.C. Kim, C.S. Park, M.S. Choi, M. Kim, H. Choi, J.S. Min, Y.S. Kim, S.W. Yoon and J.K. Ahn, J. Ethnopharmacol., 124, 189 (2009).

6. Q. Ming, F. Sun, J.W. Liu, Z.Q. Liu, S.Q. Zhang, Y.Q. Le and S.Y. Xing, Chin. J. Gerontol., 24, 267 (2004).

7. Q. Xia, Z.G. Huang, S.P. Li, P. Zhang, J. Wang, L.N. He, Chin. Pharmacol. Bull., 20, 357 (2004).

8. A. Ramirez Bosca, A. Soler, M.A.C. Gutierrez, J.L. Alvarez and E.Q. Almagro, Age, 18, 167 (1995).

9. X. Chen, H.Y. Zhong, H. Zhu, J.H.Zeng and P. Dai, Int. J. Biol. Macromol, 44, 138 (2009).

10. A.K. Singh, G.S. Sidhu, T. Deepa and R.K. Maheshwari, Cancer. Lett., 107, 109 (1996).

11. E.H. South, J.H. Exon and K. Hendrix, Immunopharm. Immunot., 19, 105 (1997).

12. K. Spelman, J. Burns, D. Nichols, N. Winters, S. Ottersberg and M. Tenborg, Altern. Med. Rev., 11, 128 (2006)

13. K. Sompamit, U. Kukongviriyapan, S. Nakmareong, P. Pannangpetch and V. Kukongviriyapan, Eur. J. Pharmacol., 616, 192 (2009).

14. L.P. Yarru, R.S. Settivari, N.K.S. Gowda, E. Antoniou, D.R. Ledoux and G.E. Rottinghaus, Poultry Sci., 88, 2620 (2009).

15. Y. Wang and M.Z. Wang, Acta Pharmacol. Sin., 36, 849 (2001).

16. M.T. Huang, W. Ma, P. Yen, J.G. Xie, J.K. Han, K. Frenkel, D. Grunberger and A.H. Conney, Carcinogenesis, 18, 83 (1997).

17. H. Matsuda, K. Ninomiya, T. Morikawa and M. Yoshikawa, Bioorg. Med. Chem. Lett., 8, 339 (1998).

18. H.S. Samaha, G.J. Kelloff, V. Steele, C.V. Rao and B.S. Reddy, Cancer Res., 57, 1301 (1997).

19. S. Zheng, H. Yang, S.Z. Zhang, X.P. Wang, L.L. Yu, J.Q. Lu and J. Li, J. Cell. Biochem., 67, 106 (1997).

20. P.S. Xie and A.Y. Leung, J. Chromatogr. A, 1216, 1933 (2009).

21. K.M. Gong, J. Ren, S.H. Tang, B.L. Tang, H.Q. Zhao and M.Y. Jin, Chin.Tradit. Herb. Drugs, 36, 1331 (2005).

22. J.Z. Wang, Y.F. Lou, J.F. Lu, X.P. He, L.X. Zheng and X.L. Deng, Chin. J. Clin. Pharm., 10, 107 (2001).

23. Y. Xie, T.J. Hang, Z.X. Zhang and D.K. An, Chin. Tradit. Herb. Drugs, 3, 600 (2001)

24. C.H. Deng, J. Ji, N. Li, Y.J. Yu, G.L. Duan and X.M. Zhang, J. Chromatogr. A, 1117, 115 (2006).

25. F.Q. Yang, S.P. Li, Y. Chen, Q.Q. Liu, W.Y. Tao, D.T. Xia and Z.H. Qiang, Chin. J. Pharm. Anal., 25, 827 (2005).

26. F.Q. Yang, S.P. Li, J. Zhao, S.C. Lao and Y.T. Wang, J. Pharm. Biomed. Anal., 43, 73 (2007).

27. B. Avula, Y.H. Wang, T.J. Smillie and I.A. Khan, Planta Medica, 75, 437 (2009).

28. R. Bos, T. Windono, H.J. Woerdenbag, Y.L. Boersma, A. Koulman and O. Kayser, Phytochem. Anal., 18, 118 (2007).

29. F.Q. Yang, Y.T. Wang and S.P. Li, J. Chromatogr. A, 1134, 226 (2006).

30. N. Baldovini, F. Tomi and J. Casanova, Phytochem. Anal., 12, 58 (2001).

31. Y.Z. Liang, P. Xie and K. Chan, J. Chromatogr. B, 812, 53 (2004). 